\title{
Trends in Biosensors for HPV: Identification and Diagnosis
}

\author{
Isaac A. M. Frías, ${ }^{1}$ Karen Y. P. S. Avelino, ${ }^{2}$ Rafael R. Silva, ${ }^{3}$ \\ César A. S. Andrade, ${ }^{2,3}$ and Maria D. L. Oliveira ${ }^{2}$ \\ ${ }^{1}$ Programa de Pós-Graduação em Ciência de Materiais, Universidade Federal de Pernambuco, 50670-901 Recife, PE, Brazil \\ ${ }^{2}$ Departamento de Bioquímica, Universidade Federal de Pernambuco, 50670-901 Recife, PE, Brazil \\ ${ }^{3}$ Programa de Pós-Graduação em Inovação Terapêutica, Universidade Federal de Pernambuco, 50670-901 Recife, PE, Brazil
}

Correspondence should be addressed to César A. S. Andrade; csrandrade@gmail.com

Received 2 April 2015; Revised 21 June 2015; Accepted 5 August 2015

Academic Editor: Michele Giordano

\begin{abstract}
Copyright (C) 2015 Isaac A. M. Frías et al. This is an open access article distributed under the Creative Commons Attribution License, which permits unrestricted use, distribution, and reproduction in any medium, provided the original work is properly cited.

The conventional methodologies used for the detection of human papillomavirus (HPV) present actually robust and reproducible advantages. However, at the same time, they involve complex protocols that sometimes are difficult to popularize. Over the first half of XX century, the adequate treatment of complex and delicate processes from a simple instrumental base seemed a fundamental and intrinsic contradiction. However, interdisciplinary trends have allowed the manipulation of tissues, proteins, and nucleic acids through innovative increasingly smaller devices. The proper diagnosis of HPV has seen great advances since biosensor researchers are employing its virus strains as models to study the interactions between the biorecognition element and the transducer. Additionally, all recent improvements and trends that material sciences, biotechnology, and data processing scientists excel for biosensors can be applied for the HPV detection platforms. In this review, we highlight the recent trends on materials, nanomaterials, and transducers for the specific detection and differentiation of HPV strains. The most influential methods for the detection and identification of these papillomaviruses include optical, electrochemical, and piezoelectric transducers; we will visit their sensibility and advantages. Additionally, we highlight the factors that contributed to the increasing importance of these biodevices as potential substitutes to conventional diagnostic methods.
\end{abstract}

\section{Introduction}

Perplexing as it may seem, the cancer research community has significantly underappreciated the enormous amount of cancer cases caused by viral infections [1], mostly because it is known that just a small proportion of humans infected with any of the oncogenic viruses will develop tumors. In the last century, at least seven human viruses have been pointed as the cause for $10-15 \%$ of worldwide human cancers cases [2]. Cancers are serious public health concerns in the developed countries and, for sure, most of aggressive cases could be avoided in first place by preventing the initial infection. Behavioral changes and vaccination, as well as the early screening of precancerous lesions, have shown to be plausible palliatives to prevent the disease.

At first glance, human papillomavirus (HPV) viruses may sound like an evolutionary machinery programmed to cause cancer; however, from the $150 \mathrm{HPV}$ genotypes that have been already identified, only about a dozen are highrisk or oncogenic types $[3,4]$. A routine practice in the medical community consists in the association of major risk factors to cancer incidences. Tobacco and alcohol consumption are regularly associated to oropharyngeal cancer as much as sexual behavior risk is assigned to anogenital cancer. However, the astonishing proportion of confirmed presence of viruses on healthy individuals that have never had those risk factors is overwhelming [5]. Although most patients infected by HPV can spontaneously eliminate the virus by their own immune system [6], some individuals can remain asymptomatic by maintaining the virus in latent form and some other immunocompromised patients may present recurrent infections [7]. Several factors such as the lesion type, size, spread, and localization will establish the risk level of the infection and will help to endorse the correct treatment.

Conventional treatments have different effectiveness levels and are selected according to the patient tolerance. Some 
of the leading conventional methods include chemotherapy $[8,9]$, immunotherapy [10], surgery [11], or the collective application of these techniques [12, 13]. Additionally, nanoparticle based delivery of anticancer drugs and therapeutic vaccines have increased the treatment efficacy while simultaneously decreasing the side effects of the traditional therapeutics [14]. The occurrence of visible epidermal manifestations as warts or condylomas is one of the symptoms of HPV infection; however, since only $1 \%$ of infected patients present the symptomatology, the diagnosis is difficult $[15,16]$. The identification of the disease in these asymptomatic cases requires specialized equipment to carefully search for internal lesions at the mucous membranes. In cases of proven cervical injury, a routine cytological analysis known as Papanicolaou test is performed over a local biopsy for histopathological analysis $[17,18]$. Beyond visual and cytological identification, molecular diagnosis is taking over as an essential method for the accurate differentiation between HPV strains, which are categorized with respect to their potential for low, intermediate, or high oncogenic risk.

Since all HPV strains are related, researchers have battled to understand and find the characteristics that differentiate every discovered strain. Often the distinction relies on the peculiar metabolism that a particular strain endures. The most common ways to differentiate the HPV involve the analysis of the protein expression ratio that provides a molecular fingerprint of the oncogenic potential within a histopathological sample $[19,20]$. Considering the fact that some HPV strains are more related between them than to the others, DNA analyses are often required for the accurate identification of the strain. DNA analyses are quite heterogeneous and are based on the complementarity principle of the DNA strands. For instance, we can identify the target amplification of a precise fragment of nucleic material by the polymerase chain reaction (PCR) and by signal amplification of an oligonucleotide hybridization assay [21, 22]. Although PCR associated techniques present high rates of sensitivity and specificity, most of these techniques are mainly used by research centers and/or specific health services. Some of the reasons include the time consuming and complex protocols that usually require specialized skills for the correct operation of the instruments and fulfillment of the methods [23].

Fortunately, the research on cancer has reached a maturity level of awareness that allows the population to realize that viruses are in fact the cause of a great proportion of cancers. The alarming discovery that certain high-risk strains of HPV caused assured $100 \%$ of invasive cervical cancer has instigate a global awareness about cervical cancer prevention and, most essentially, the development of other cancers prophylactic vaccines [24]. Regular vaccines use viral vectors to promote immune response, and, more recently, DNA vaccines have been developed to control tumor-expressed antigens [25]. The employed plasmid vectors are safe and present low immunogenicity, so they can be constantly administered. Further researches have been demonstrated to increase their efficiency by designing nanometrical delivery systems as nanoparticles, micelles, and fibers [26].

After HPV16 and HPV18, 10 more HPV strains are known to cause cervical carcinomas [61]. Some researchers have reached a milestone, where the precise identification of HPV types has become extremely important. They propose to follow the ecological competitive exclusion principle to create an artificial substitution of high-risk HPV types for those of reduced risk [3]. In addition, the detailed identification of all different strains within a sample is of great importance to epidemiological studies and involves major and interesting new obstacles to overcome, for example, the correct identification of HPV strains that are known to be genetically close related like HPV6 and HPV11.

Because of the large amount of different HPV types, it is reasonable to think that the current competence of vaccine design technology is insufficient to provide enough protection. Despite the fact that the research on individual strains proceeds slowly, the research on biosensors has not delayed its development. Nowadays, biosensor researchers have more tools to design better techniques to apply and help to control viral epidemics. Live vectors characterization, peptide/protein expression and interaction, DNA vaccine design, and whole cell-based treatment approaches [62] are some of the explored topics that are applied on viral sensing and detection. In the case of genosensors, as much as the genomic databases improve, cancers will be easier to detect and diagnose.

\section{Biosensors for HPV as Alternative Diagnostic Tools}

Over the years, the progress of biotechnological research has contributed to the development of biologic sensor devices $[63,64]$. Biosensors are portable analytical devices constituted by at least one biological molecule. The strategies to obtain these biosensors combine the specificity of the biological probe with the analytical capacity of the transduction methods [65, 66]. In addition, materials at the nanometer scale as nanoparticles [67], nanotubes [28], nanofibers [68], and nanocomposites [69] have been used to achieve the nanostructuration of these devices. The diversity of structures provides tailored interfacial modification alternatives with the purpose of amplifying the analytical signal and increasing the sensibility of the biosensor [63]. The challenge to construct these nanometrical systems relies in the need to preserve the biological activity of the probe as well as the transducing activity of the nanostructure [70]. For these reasons, a detailed study of the physical-chemical properties of both constituents should be performed.

The device requires the efficient immobilization of antibodies, peptides, aptamers, or nucleic acids over the surface of a transducer, which are responsible for the analyte recognition and will execute a measurable response signal proportional to the analyte concentration [71-74]. Besides covalent functionalization of nanoparticles (known for allowing a strong and controlled immobilization of the probe over the surface of the sensor), most immobilization strategies involve simple methods. In general, mixtures or emulsions of two or more materials previously known for their individual properties are performed, for example, nanoparticles 

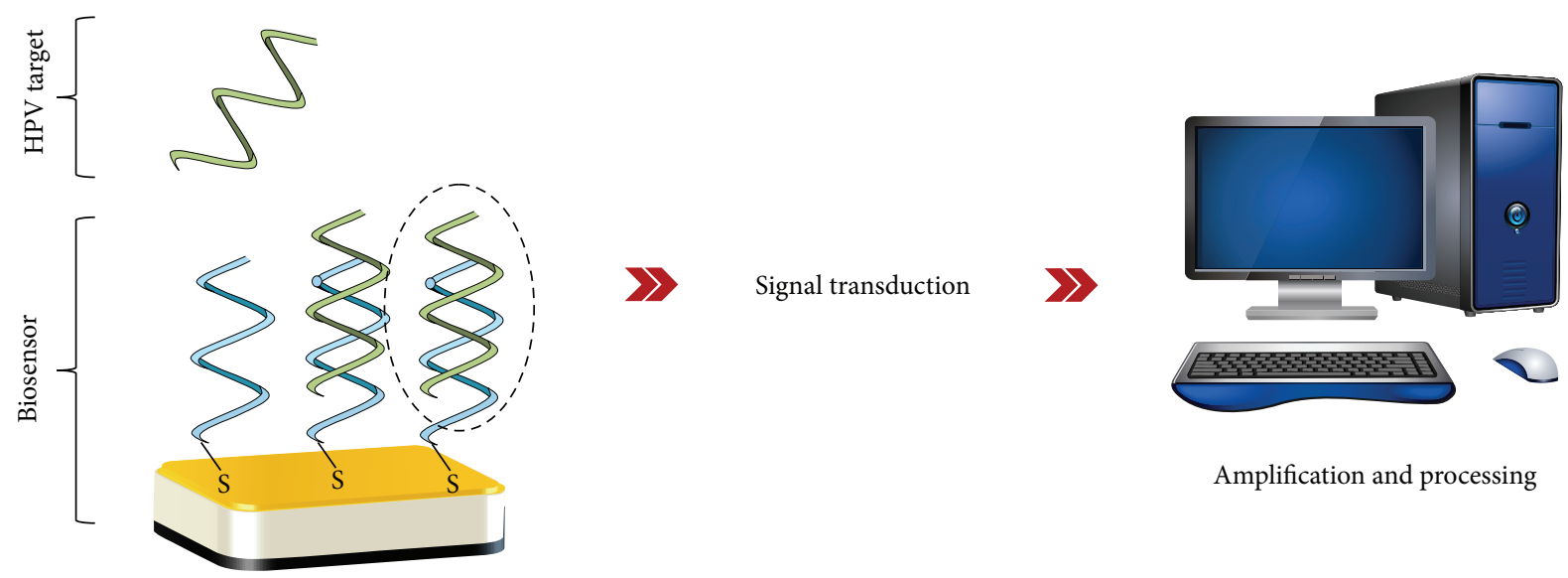

Amplification and processing
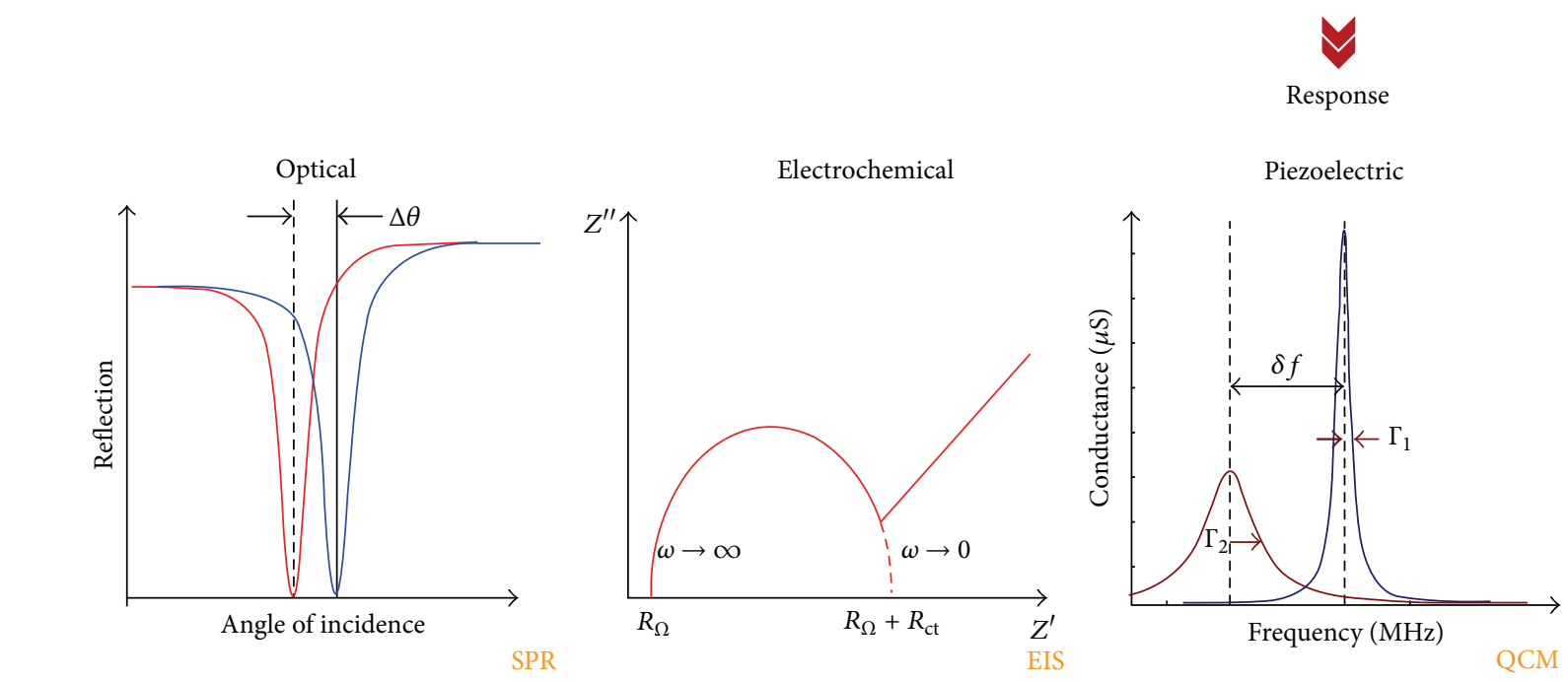

FIGURE 1: Schematic representation of a biosensor developed to detect HPV. The response arising from the biospecific interaction between the oligonucleotide probe and the HPV target DNA will be transduced into a measurable signal, which will be amplified and processed by computer software. The main types of signal transduction methods used in biosensors for HPV are optical, electrochemical, and piezoelectric. In addition, the signal conversion can be accomplished through SPR, EIS, and QCM techniques [31, 70, 103].

of biodegradable polymers as poly(lactic acid), poly(D,Lglycolide), and chitosan, among others, which are conjugated with biorecognition drugs as therapeutic cancer vaccine formulations $[75,76]$. As another example of versatility, we find magnetic nanoparticles. These nanomaterials have been conjugated with an enormous amount of fluorescent dyes, polymeric matrixes, and biologic macromolecules, among others, to provide the magnetic property to innumerous in situ HPV biosensor applications [77, 78].

The incursion of nanotechnology into biology has been catalyzed by the positive and important role that analytical methodologies and automation have over the equipment efficiency and effectivity, thus allowing the rapid progression of sensor systems $[63,79]$. Nowadays, we are presented with innumerous types of transducers that can be used for the construction of biosensors, and according to the physical principle of transduction, we find it easy to classify them into electrochemical, optical, piezoelectric, and magnetic [72, 73, $80,81]$. Along with a representation of a generic biosensor constructed for HPV detection, we show in Figure 1 the main signal transduction methods currently used.
Compared to the conventional identification techniques, the biosensors dedicated to the molecular diagnosis and detection of HPV strains prove themselves less complicated and exempt from prolonged experimentation processes and purification requirements $[35,38,68]$. The interest towards biosensors is growing due to the broad potential that these devices provide in terms of high sensitivity, simplicity, low cost, and small sample volume requirement. The amount of recent publications in biosensors is the proof of the interest that researchers have in the development of effective and stable sensor platforms for application in clinical analysis $[82,83]$. In this review, we will provide an overview of the trends and advances in the field of biosensors developed for the diagnosis and detection of HPV. We will compare the detection limits obtained for each transduction technique and the convenience of their use.

2.1. Electrochemical Biosensors. The improvement on electrochemical biosensors walks along with the advances of analytical chemistry, a science dedicated to measure the 
structure, composition, distribution, and interaction of matter. The purpose of the electrochemical research is to design sensitive, selective, and specific detection strategies, measuring principles and analytical methodologies. In addition, the automation processes provided better construction strategies for obtaining biosensors with increased analytical performance $[63,64,84]$. Since Clark and Lyons first developed an electrochemical biosensor for glucose in 1962, this transduction method represents the main class of biosensors reported in the literature and they are by far the most commercially successful $[74,80,85,86]$. In fact, Vernon et al. developed a bioelectronic detection platform for the detection of multiple HPV types. The design of the model system is structured on gold electrodes where self-assembled monolayers of immobilized oligonucleotides that are specific for HPV genotypes are formed [27].

The electrochemical biosensor is a device composed of a biological recognition element that is associated with an electrochemical transducer capable of providing selective quantitative or semiquantitative analytical information [72, 87]. These biosensors require electroanalytical techniques (such as potentiometry, amperometry, voltammetry, conductometry, and impedometry) $[73,88]$ to measure the transduced output signal and to characterize the electrochemical changes in the system caused by the molecular recognition process.

As we have already stated, electrochemical biosensors are the most utilized devices for screening and diagnosing clinical analysis $[65,74]$. In this sense, we show in Table 1 the trends on electrochemical techniques for biodetection of HPV [35, 38, 68]. The electrochemical biosensors are promising diagnostic techniques for HPV, because of their tendency to miniaturization and due to their fast response, simplicity, and low cost instrumentation [88]. Although the regeneration of the sensor platform might minimize the cost of the analysis, only a few publications report reusable electrochemical biosensors [28, 32].

The actual interest on multiplex assays [31], which refers to the fulfilment of a full range of laboratory tests in the form of a centimeter square microarray, is evident. Also the incorporation of technological advances as microfluidic channels is starting to venture willing to improve the already stablished multiplex assays. The most frequent platform to immobilize the oligonucleotides is a gold electrode, achieving the interaction through thiol-gold covalent bonding. The process can be performed in the presence of a secondary reporter probe (which will serve as a label during the measurement process) as tetramethylbenzidine (TMB), horseradish peroxidase, methylene blue, or hematoxylin providing an amplified electrochemical response combined with greater specificity [29, 31, 32, 36].

Besides the already mentioned gold electrodes, in the last five years, label-free electrochemical microarrays have been used extensively for the detection of different HPV16 antibodies [34, 35, 37, 39]. These label-free platforms are developed through the immobilization of the biorecognition probe atop of an interdigitated gold or platinum electrode. The signal transducers are widely diverse, pencil graphite surfaces [30, 33], carbon surfaces modified with linear polysaccharides [35], plain glassy carbon surface [34], or poly(methylmethacrylate) substrate recovered with a thin gold film [38]. Additionally, more sophisticated nanostructured ones as graphene/gold nanoparticles (AuNPs), nanorod/poly(thionine), or polyaniline-multiwall carbon nanotube (MWCNT) film $[39,68]$ have been used to construct biosensors committed to detect and differentiate HPV strains. These platforms facilitate the study of the output signal by cyclic voltammetry (CV), square wave voltammetry $(\mathrm{SWV})[33,35]$, differential pulse voltammetry (DPV) $[30,68]$, and electrochemical impedance spectroscopy (EIS) [68].

After analyzing the most recent developed electrochemical biosensors for the identification of HPV, we noticed that the sensor platform constructed by Wang et al. holds the lowest detection limit reported in the literature for the DNA of HPV16. Interestingly, the transducer of the platform was designed from single walled carbon nanotube arrays coated with gold nanoparticles, atop of which the self-assembly of single-stranded DNA probe was promoted. Electrochemical impedance was used to verify the high sensitivity, great stability, and good regeneration ability of the biosensor with a detection limit up to one attomole of HPV16 DNA [89].

From the presented alternatives, we highlight the use of nanomaterials, particularly carbon nanotubes and gold nanoparticles, as strategic components to improve the analytical performance of electrochemical biosensors [38, 39, $68,89]$. The cited nanomaterials exhibit not only combined dielectric and optical properties but also a high surfaceto-volume ratio, biocompatibility, and high conductivity, allowing direct charge transfer between the biomolecule and the electrode surface [90-92]. Thus, it is possible to obtain biosensors with higher sensibility and ultralow detection limit.

In addition, there is a notable interest on the development of ultrasensitive methods for the detection of particular papillomavirus strains, especially the high-risk associated HPV types 16, 18, and 45 [31, 32, 68]. In spite of these electrochemical biosensors being prototypes and requiring additional studies of reproducibility, stability, and validation, they show potential to become valuable alternatives or even the new conventional diagnostic methods [93].

2.2. Optical Biosensors. Visual differentiation techniques are widely spread over important areas of modern life like food safety, security, and environmental monitoring, in medicine and, of course, in HPV detection [66]. Several of the first methods to detect diseases and pathological infections were optical based methods. The Papanicolaou test, a worldwide famous cervical cytology exam performed to detect HPV, was developed to exploit optical techniques as microscopy. In recent decades, other optical alternatives in the form of optical biosensor, also named optrodes, have grown robust because of the facility to differentiate the positive and negative samples by color changes produced by differential staining and fluorescence labeling $[94,95]$. In Table 2, we present the comparison of some features used on recent publications for 


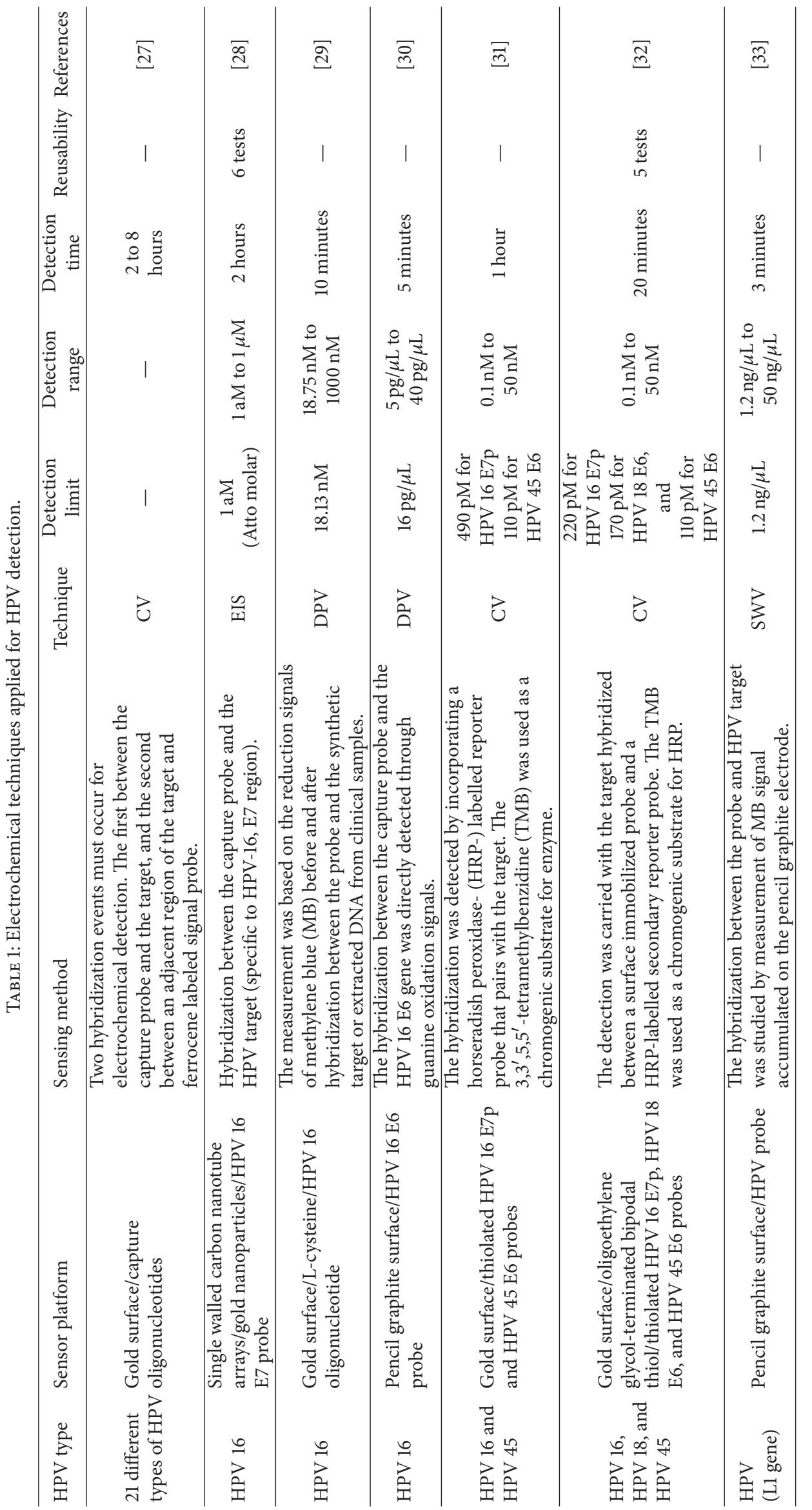




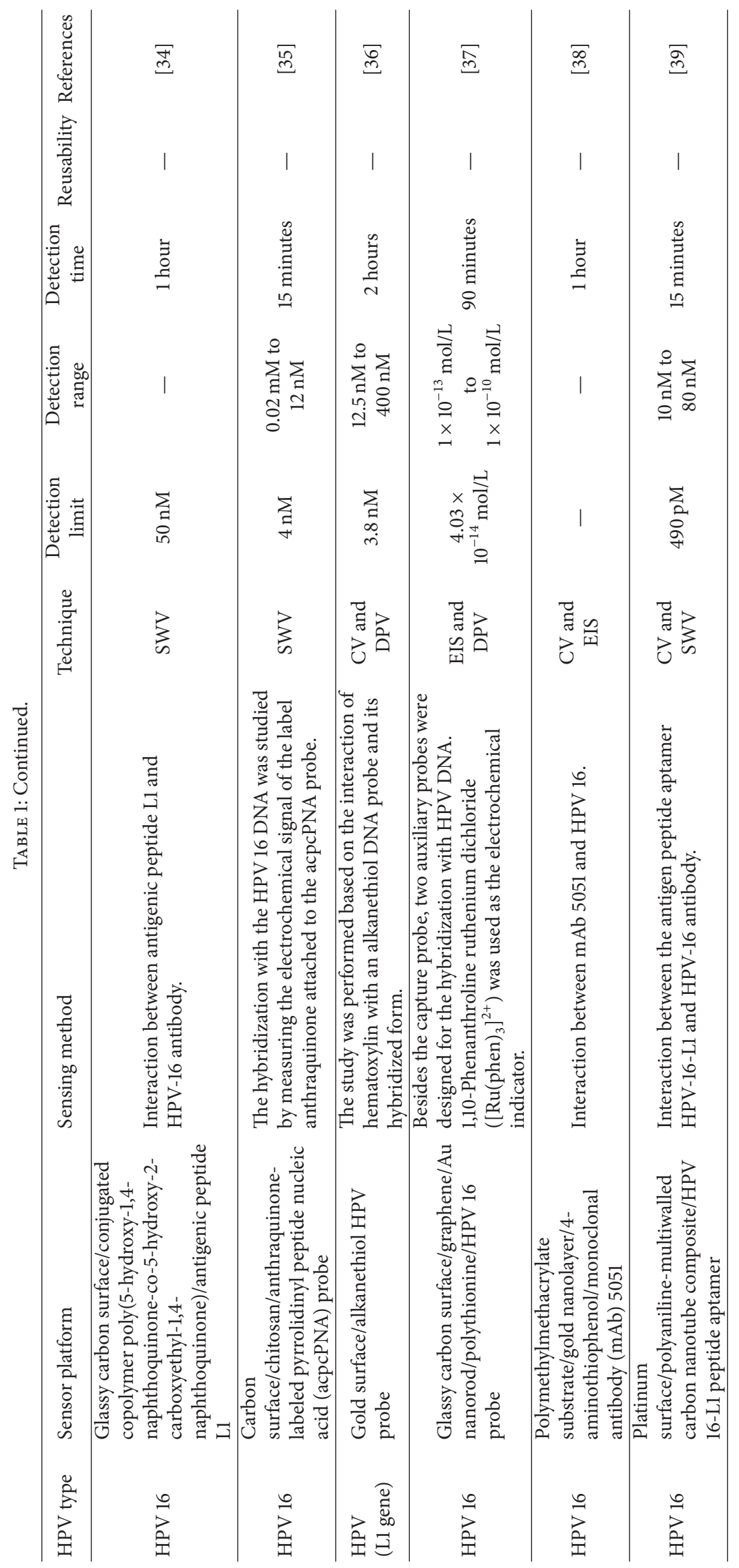




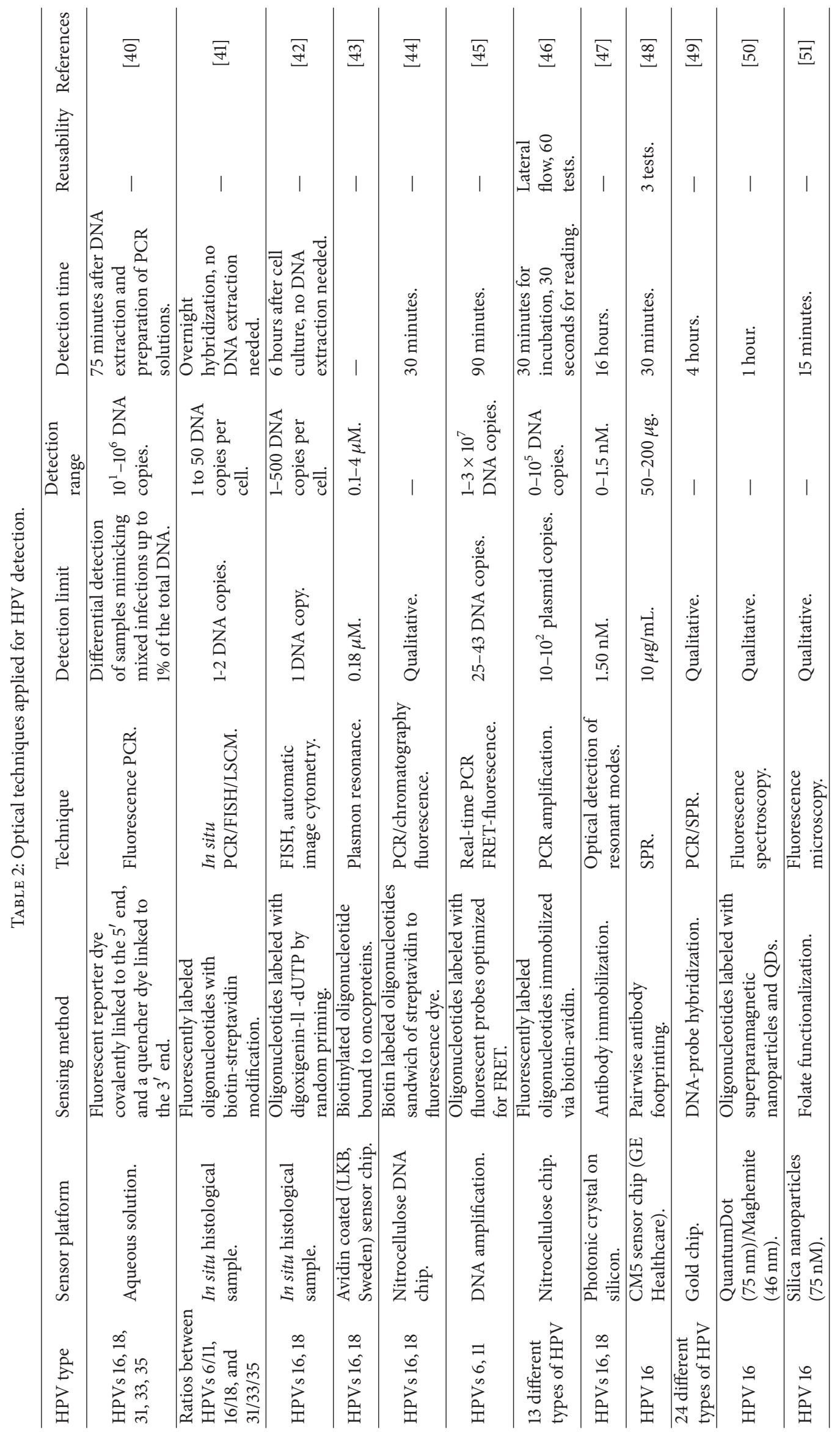




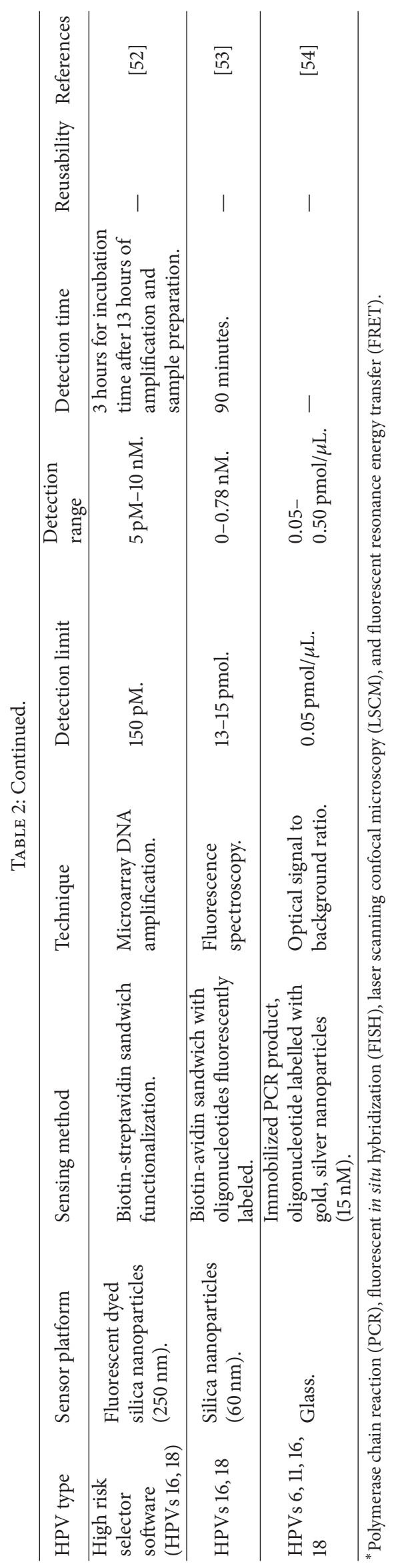


the identification and detection of HPV strains by optical transducers. When applied to conventional methods, fluorescent and color labels provide an upgrade in the analysis of tissue samples, allowing fast and automatized diagnosis based on the differential staining of cancerous cells. A technique frequently employed to diagnose HPV is the fluorescent in situ hybridization (FISH); this technique provides the possibility to examine the tissue sample at the same time that the fluorescent label probe signals the specific DNA region for which it was designed.

When PCR assays reached HPV diagnosis [96], the use of fluorescent molecules impelled not only the detection but the quantitation of oncogenic HPV strains by real-time PCR (RT-PCR) [40]. Mostly, fluorescent nanoparticles provide a labeled transduction methodology that has proven to be very useful for the identification of HPV viral genome after PCR amplification [44]. To date, RT-PCR is the only technique capable of identifying closely related HPV strains. The group of Poljack has demonstrated a beautiful use of fluorescence resonance energy transfer (FRET) coupled with RT-PCR to achieve the identification of 19 different HPV strains that are important because of their oncogenic risk [45]. They successfully identified several HPV strains mixed in the same sample, with a presence as low as 25-43 DNA strands per strain. Despite the advances on terms of specificity and sensibility, PCR based methodologies are being rapidly challenge by optrode methodologies. Some of these alternative biosensors provide a significant reduction in diagnosis time besides an increased portability and facility of use out of controlled laboratory environment. Although optrodes do not hold the lowest detection limit, when they are combined with spectroscopic techniques, they represent one of the methodologies with the highest sensibility. For instance, $\mathrm{Li}$ and col. [54] developed a glass chip with immobilized HPVs $6,11,16$, and 18 oligonucleotides. The hybridized target DNA was labeled with gold and silver nanoparticles besides a fluorescent molecule. Their strategy attained a $0.05 \mathrm{pmol} / \mu \mathrm{L}$ detection limit.

The most common analytical techniques used to measure the transduced signal of optical biosensors include absorption, fluorescence, phosphorescence, Raman, refraction, and dispersion spectroscopies; also, there is surface plasmon resonance (SPR) [97]. Biosensors that make use of the surface plasmonic waves of metallic substrates to detect the interaction between the target analyte and the biorecognition element are actually monitoring the change in the refractive index (RI) at the analyte-sensor interface. The RI changes produce a variation in the propagation constant of the surface plasmon wave that will produce the reading [98]. One of the signatures of SPR is its convenience as a labelfree sensing principle, avoiding the use of radioactive and fluorescence markers. Since SPR measures the mass of the material binding to the sensor surface [99], the technique is not suitable for studying small analytes $<2 \mathrm{kDa}$; however, SPR has been proposed as an optimal transducer to identify HPV strains among other viruses [100] based on size and mass differences or as an immunologic methodology. In addition, the proper functionalization of the SPR substrate provides high specificity towards selected HPV strains. Once the substrate is properly functionalized, the methodology can perform several diagnoses and regeneration cycles in a row, resulting in a reduction of time when compared to PCR based methodologies. As an immunologic methodology, SPR achieved the detection limit of $10 \mu \mathrm{g}$ of HPV16 expressed protein per $\mathrm{mL}$.

The use of fluorescent nanoparticles as transducers requires the synergy between the nanostructure and one or several distinct biological materials as enzymes, nucleic acids, or antibodies to the capsid of the target virus. Some of the most important characteristics of nanoparticles are its surface and then the transduction method that the nature of the nanoparticle involves. In the case of fluorescent nanoparticles, quantum dots (QD) are semiconductor nanoparticles with exceptional optical properties such as fluorescent emission controlled by the size of the nanoparticle. Some quantum dots are assembled as core-shell structures where magnetic core plays an important role in recovering the particles from the sample. Nanoparticles are generally exploited by bioconjugation, that is, by the intelligent mixing of the nanostructure with some biological molecules as DNA or RNA oligonucleotides; this conjugation is made to favor the binding of small oligonucleotides that are complementary to HPV DNA. These kinds of bioconjugated systems have demonstrated to differentiate between HPV16 and HPV18 strains mixed in the same sample [101]. Usually utilized as reporters or signal enhancers $[52,54]$, nanoparticles are designed based on their combination with another technique. In this manner, silica nanoparticles (SiNPs) are commonly mixed with fluorescent molecules to achieve the prescreening of many HPV genotypes [51]. Nanoparticles can also be covalently linked to oligonucleotides as Yu-Hong and col. described [50]. In their method to detect HPV16, they functionalize QD and magnetic nanoparticles to DNA probes. When both probes attach to a HPV16 DNA specific region, then the labeled DNA responds to an applied magnetic field and, at the same time, presents luminescence from the QD. Even though these kinds of qualitative diagnostic methods are developed to serve a single sample, they are advantageous because they are portable and feature simplified handling.

Fluorescence is an important luminescent property of certain molecules. When fluorescent systems are engineered to recognize a certain HPV strain, not only does the fluorescence of the molecule provide in situ evidence of the existence of the expected strain but also its quantification can be easily achieved. An exact amount of energy must be supplied to the molecule so that it can get into the excited state, from which the luminescence will occur. Electromagnetic radiation is the most common way to provide this energy, but there are other quite rare and convenient ways to supply this energy as by heat, by frictional force, and by electron impact or crystallization [102]; all these alternatives are still to be exploited for the specific detection of HPV. For the most part, optical transducers and optical biosensors are gaining research interest; actually, Qiagen N.V., a molecular diagnostics company, has developed and commercialized the first molecular diagnostic to screen for high-risk HPV strains designed for low-resource clinical settings [103]. 
TABLE 3: Piezoelectric biosensors for HPV detection.

\begin{tabular}{|c|c|c|c|c|c|c|}
\hline HPV type & Sensor platform & Techniques & Application & Sensibility & Detection limit & References \\
\hline $\begin{array}{l}\text { HPVs } 6,11, \\
16,18\end{array}$ & $\begin{array}{l}\text { HPV probes with a } \\
\text { disulfide group }\end{array}$ & QCM & $\begin{array}{l}\text { Qualitative results from QCM versus } \\
\text { dot-blot hybridization }\end{array}$ & $\begin{array}{l}25 \mu \mathrm{M} \text { of } \\
\text { predigested } \\
\text { PCR products }\end{array}$ & $-\Delta F=48 \pm 5 \mathrm{~Hz}$ & [55] \\
\hline HPVs 16,18 & $\begin{array}{l}\text { Biotinylated HPV } \\
\text { probes via } \\
\text { streptavidin } \\
\text { anchoring }\end{array}$ & QCM & $\begin{array}{l}\text { Simultaneous identification and } \\
\text { genotyping HPVs } 16 \text { and } 18\end{array}$ & $\begin{array}{l}50 \mathrm{nM} \text { of PCR } \\
\text { products }\end{array}$ & $-\Delta F=\leq 3 \mathrm{~Hz}$ & {$[56]$} \\
\hline HPVs 6, 11 & HPV probes & QCM & $\begin{array}{l}\text { Detection of single strand-PCR } \\
\text { products in temperature changes by } \\
\text { metal clamping piezoelectric sensor }\end{array}$ & $25 \mu \mathrm{M}$ & $-\Delta F=82 \pm 3.7 \mathrm{~Hz}$ & {$[57]$} \\
\hline HPV 58 & $\begin{array}{l}\text { Biotinylated LAMP } \\
\text { HPV products via } \\
\text { avidin anchoring }\end{array}$ & LAMP-QCM & $\begin{array}{l}\text { Real-time amplification and } \\
\text { hybridization to HPV } 58 \text { probe }\end{array}$ & $\begin{array}{l}1-10^{6} \text { plasmid } \\
\text { clones }\end{array}$ & $\Delta F=28.3 \mathrm{~Hz}$ & {$[58]$} \\
\hline $\begin{array}{l}11 \text { different } \\
\text { types of } \\
\text { HPV }\end{array}$ & $\begin{array}{l}\text { Biotinylated HPV } \\
\text { probes via avidin } \\
\text { anchoring }\end{array}$ & QCM & $\begin{array}{l}\text { QCM sensor replacement of } \\
\text { traditional method, HPV detection in } \\
\text { gel electrophoresis for QCM system }\end{array}$ & $\begin{array}{l}10^{3} \text { plasmid } \\
\text { clones }\end{array}$ & $\Delta F=44.7 \mathrm{~Hz}$ & {$[59]$} \\
\hline HPV 16 & $\begin{array}{l}\text { Alkanethiol } \\
\text { self-assembling } \\
\text { monolayer }\end{array}$ & QCM-D & $\begin{array}{l}\text { Detection of antigens (cytoplasmic } \\
\text { proteins) from cancer cell lines by } \\
\text { HPV }\end{array}$ & \multicolumn{2}{|c|}{ Bayesian classifier dependent } & {$[60]$} \\
\hline
\end{tabular}

${ }^{*}$ Loop-mediated isothermal amplification (LAMP).

2.3. Piezoelectric Biosensors. The recent success in the molecular diagnosis of HPV by electrochemical and optical transducers based on the sequence-specific detection of nucleic acids (DNA or RNA) encouraged the development of diagnostic tools based in other novel transducer methods as the piezoelectric biosensors. Biosensors are important alternatives to the conventional molecular biology techniques like the blotting methods, because they hold associated advantages in terms of cost, run time, and real-time monitoring [104]. Piezoelectric biosensors exploit a secondary but not less important aspect of the electrochemical biosensor, the gravimetric analysis of the biosensor surface. In each electrochemical reaction, mass changes occur as material is deposited or lost from the surface of the transducer, and the monitoring of these changes simultaneously with the electrochemical response provides the piezoelectric biosensor with clear advantages over the electrochemical biosensor alone. These gravimetric transducers have shown to be able to achieve good sensitivity and specificity for the target molecule $[105,106]$.

The quartz crystal microbalance (QCM) sensors consist of cavity resonators constructed over a piezoelectric crystal substrate, which will accumulate electrical charge in response to the applied mechanical stress. The most common method to immobilize the biocompatible layer is achieved by the physical adsorption of the biological probe over the quartz balance; this kind of nonspecific interaction results in the strong collective action of a large number of relative weak bonding interactions. However, the recent trend for the use of QCM biosensors for the detection of HPV viruses prefers a more specific strategy of immobilization involving biotinylated HPV probes. In Table 3, we present the comparison of some features used in recent publications for the identification and detection of HPV strains by piezoelectric transducers.
The specificity of the biotin/streptavidin bonding is used in conventional assays as the enzyme-linked immunosorbent assay (ELISA). The binding mechanism between biotin and streptavidin results in long-term stable anchoring [107]. Dell'Atti et al. developed a biosensor based on such processes of immobilization for the recognition of HPV 16 and 18 types. Their methodology allowed monitoring real-time hybridization by frequency changes, which resulted in HPV type differentiation. They achieve the identification within a $50 \mathrm{nM}$ detection limit of PCR-amplified short DNA strands. Furthermore, the stability of the probe-surface interaction allowed the regeneration of the system up to fifteen times without losing sensitivity [56]. Moreover, this technique presented some advantages over conventional molecular techniques that require many steps to achieve the same result $[108,109]$.

Fu et al. have constructed one of the first HPV genosensors based on QCM piezoelectric. This group aimed at the detection and identification of HPV types $6,11,16$, and 18 from pathologic biopsy samples. The strategy involved the adsorption of HPV oligonucleotides functionalized with disulfide groups atop the surface of a QCM disc. The system presented high sensibility (up to 95\%), which is comparable to the result obtained by the combination of PCR and dotblot technique $[55,110]$. This label-free technique offers some benefits like rapidness, convenience, low cost, and feasible multiple sensors building on several QCM plates [103].

One important aspect that is relevant for the correct use of DNA based QCM piezoelectrics is temperature. Maintaining a constant temperature during the formation of the biocompatible layer has been shown to influence its eventual thickness. As a result, the frequency pattern of the samples is modified as well [111]. Consequently, the complementary principle of nucleic acids allows real-time monitoring of the hybridization processes that result from the change in 
oscillation frequency of the QCM system after the double strand is formed [57, 112, 113]. Chen et al. [57] demonstrated that by maintaining the PCR products (amplicon) at low temperatures $\left(\sim 4^{\circ} \mathrm{C}\right)$ they could avoid the self-hybridization of DNA, resulting in a diagnosis with increased sensibility and accuracy.

Because of the deep impact that temperature has over the stability of the resonance frequency, techniques that depend on thermal cycling are severely limited. For this reason, alternatives that provide the amplification of a genomic region at constant temperature have been of great advantage. Loop-mediated isothermal amplification (LAMP) has adhered to QCM piezoelectrics with tremendous success. LAMP provides genomic amplification with high sensitivity, specificity, and rapidity [114]. Recently, Prakrankamanant et al. developed a prototype system to monitor the differences in the resonance frequency by QCM-LAMP to detect the highrisk strain HPV 58. The amplicon obtained by LAMP was biotinylated and then anchored to the avidin-coated surface of the sensor platform. Differently from conventional LAMP, the incorporation of QCM real-time monitoring system allowed a rapid and quantitative detection of HPV [58].

The same research groups aimed to increase the scope of their biosensor by immobilizing biotinylated probes for 11 high-risk types of HPV. This technique showed good accuracy for all probes with sensitivity up to $10^{3}$ copies $/ \mu \mathrm{L}$; their results are showed to be comparable to coupled PCR amplification and electrophoresis based analysis. Although the operational time of QCM-LAMP is similar to the conventional PCR/electrophoresis technique, the QCM prototype stands out since no labeling is required and because the constant system temperature is close to $4^{\circ} \mathrm{C}$. For certain, this new tool represents a milestone for piezoelectric biosensors and opens the path to complement the exploration of the interactions occurring on top of the electrochemical biosensor [59].

As an alternative to the previously described DNA biosensors, Mobley et al. used a different approach for the QCM piezoelectric technique; it is by the dissipation frequency monitoring (QCM-D) instead of the resonance frequency. Commonly applied in the fields of biophysics, biomaterials, cell adhesion, and drug discovery, this interfacial acoustic technique is a special type of QCM that serves to analyze the thickness of a film in a liquid environment [60]. In their study, they attained to distinguish between HPVpositive and HPV-negative cells based on antigen protein expression from a prelysed cancer cell line. Furthermore, their theoretical guidelines, based on linear discrimination, were useful for the analysis of the output signals of other immunosensor platforms and for the diagnosis of diseases. However, these models still require standardization to validate their results.

2.4. Magnetic Biosensors. Biosensors based on magnetic materials have presented a distinctive alternative to identify and diagnose diseases. The response signal occurs in a similar fashion than in other transducers; at the surface of the magnetic material, there is a specific biological probe immobilized and ready to interact with its counterpart found on a sample suspected to contain biologic traces of HPV. Not only have these methodologies allowed the physical separation of the substrates by magnetic field, but also there are some magnetic transducers that are able to compete with the specificity and sensibility threshold that optical transducers might detent in terms of quantification of the transduced signal [115-117].

Throughout Section 2, we have given several examples about how magnetic materials are employed in the form of nanoparticles to provide, not only but mostly, their magnetic characteristic in order to physically separate the functionalized magnetic beads from the working solution. However, over the last decade, magnetoresistive materials have been explored in the form of multilayered films (alternating layers of magnetic and nonmagnetic materials) or granulated substrates (magnetic islands inserted into a nonmagnetic material) to determine the advantages of their use as transducer materials in biosensors. In simple words, the magnetoresistance effect occurs when, under the presence of a magnetic field, the magnetic material experiences a change in its global electrical resistance.

These materials are very susceptible to magnetic fields; for this reason, even a $10 \mathrm{~nm}$ size magnetic nanoparticle might create a measurable signature of its close proximity to the magnetoresistive substrate [118], and actually this is the sensing principle behind its known great sensibility.

In spite of the novelty of the methodology, there are few reports about its use in the detection of HPV [119]. For instance, $\mathrm{Xu}$ et al. developed a multilayered system for the selective detection of HPV 16, 18, 33, and 45 subtypes. The respective DNA probes were immobilized over the surface of the biosensor to propitiate the capture, by hybridization, of the complementary targeted DNA (if present on the sample); the methodology of immobilization follows the trend used in other transducers (Figure 2).

To immobilize the probe on the surface, the interaction between amine and carboxylic acid groups is used, while the target DNA is functionalized at the loose end with biotin. To quantify the amount of hybridized target DNA, the biosensor is then exposed to magnetic nanoparticles that will bind to the biotin, because they were previously functionalized with avidin. Finally, the close presence of the magnetic nanoparticles interferes with the magnetoresistive material, creating a response signal equivalent to the amount of hybridized target DNA. This methodology was able to reach $90 \%$ of accuracy and a sensitivity around $10 \mathrm{pM}$ of target DNA; in addition, the development of these biodevices presents low cost, rapid detection, and reliability [120].

\section{Conclusion}

The proper diagnosis of HPV infection is essential for the prevention of cervical cancer. The implementation of effective therapeutic strategies requires the development of biosensors for the detection and identification of HPV types. To this date, optical, electrochemical, and piezoelectric materials are the main transducers used to develop biosensors. Among 


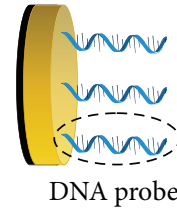

(a)

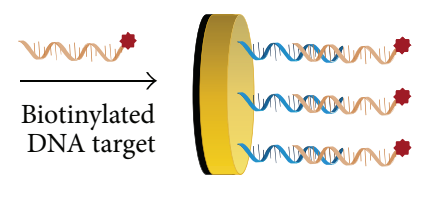

(b)

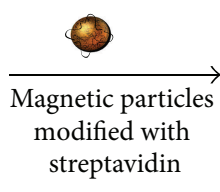

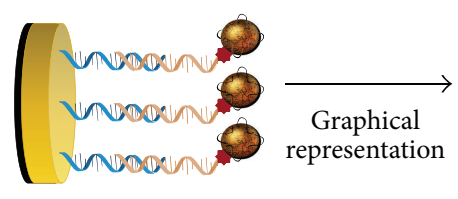

(c)

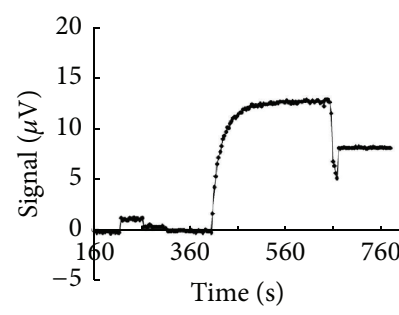

(d)

FIGURE 2: Schematic representation of a magnetic genosensor for the detection of HPV. The DNA probe was immobilized on the transducer surface (a). Then, biotinylated DNA target was hybridized (b). Magnetic particles modified with streptavidin were added on the genosensor (c). Measuring the magnetic signal could characterize the bioactivity of biodevice (d). It is important to highlight that the magnetic signal intensity is proportional to the number of biospecific interactions between the streptavidin molecules and the biotin groups.

the most sensitive techniques available to study the biorecognition activity of the sensors, we highlight the fluorescent spectroscopy, EIS, and QCM.

We notice a rapid growth in technological improvements for the development of simple, cost-effective, and accurate rapid diagnostic tests. The sensitivity and detection limit are essential parameters for the evaluation of these biodetection methodologies. However, other characteristics as the specificity, propensity to cross-binding interference, experimental simplicity, and cost should be considered. For instance, it was verified that the use of nanostructures (as carbon nanotubes and gold nanoparticles) enables the construction of electrochemical biosensors with lower detection limits. Notwithstanding, improvements in the design and manufacturing should be considered to achieve the commercial incursion of these devices, since their reuse is limited.

The ability to fast regenerate the substrate after a diagnosed sample is of great importance and affects directly the cost of the methodology. In this sense, QCM and nitrocellulose substrates have managed to get more than 10 diagnoses without losing sensibility; also, microfluidics are helping to create in-flow diagnostics to first allow the sensing to occur, quickly wash the substrate, and then offer a new sample to diagnose.

Thus, future researches should explore new strategies to enhance the immobilization and to increase the stability of bioreceptors. The development of methodologies that facilitate the use of biosensors out of controlled laboratory environment is of great importance for the popularization of these methodologies. Furthermore, evaluating the performance of the biosensors by facing real samples, such as blood and other body fluids, will verify the real potential of these new molecular methods to confirm the clinical diagnosis of HPV.

\section{Conflict of Interests}

The authors declare that there is no conflict of interests regarding the publication of this paper.

\section{Acknowledgments}

The authors are grateful for the support provided by the Brazilian National Council for Scientific and Technological
Development (CNPq Grants 310305/2012-8 and 310361/20125), Fundação de Amparo à Ciência e Tecnologia do Estado de Pernambuco (FACEPE), and Rede de Nanobiotecnologia/ CAPES. Silva and Morales would like to thank FACEPE and CAPES for their respective scholarships.

\section{References}

[1] P. S. Moore and Y. Chang, "Why do viruses cause cancer? Highlights of the first century of human tumour virology," Nature Reviews Cancer, vol. 10, no. 12, pp. 878-889, 2010.

[2] D. M. Parkin, "The global health burden of infection-associated cancers in the year 2002," International Journal of Cancer, vol. 118, no. 12, pp. 3030-3044, 2006.

[3] J. E. Tota, A. V. Ramanakumar, M. Jiang et al., "Epidemiologic approaches to evaluating the potential for human papillomavirus type replacement postvaccination," American Journal of Epidemiology, vol. 178, no. 4, pp. 625-634, 2013.

[4] M. Schmitt, B. Dondog, T. Waterboer, M. Pawlita, M. Tommasino, and T. Gheit, "Abundance of multiple high-risk human papillomavirus (HPV) infections found in cervical cells analyzed by use of an ultrasensitive HPV genotyping assay," Journal of Clinical Microbiology, vol. 48, no. 1, pp. 143-149, 2010.

[5] A. R. Kreimer, A. Villa, A. G. Nyitray et al., “The epidemiology of oral hpv infection among a multinational sample of healthy men," Cancer Epidemiology Biomarkers \& Prevention, vol. 20, no. 1, pp. 172-182, 2011.

[6] I. Frazer, "Correlating immunity with protection for HPV infection," International Journal of Infectious Diseases, vol. 11, supplement 2, pp. S10-S16, 2007.

[7] O. Aynaud, D. Piron, R. Barrasso, and J.-D. Poveda, "Comparison of clinical, histological, and virological symptoms of HPV in HIV-1 infected men and immunocompetent subjects," Sexually Transmitted Infections, vol. 74, no. 1, pp. 32-34, 1998.

[8] W.-Y. Zhu, A. Blauvelt, B. A. Goldstein, C. Leonardi, and N. S. Penneys, "Detection with the polymerase chain reaction of human papillomavirus DNA in condylomata acuminata treated in vitro with liquid nitrogen, trichloroacetic acid, and podophyllin," Journal of the American Academy of Dermatology, vol. 26, no. 5, part 1, pp. 710-714, 1992.

[9] K. Niwa, K. Tagami, Z. Lian, J. Gao, H. Mori, and T. Tamaya, "Topical vidarabine or 5-fluorouracil treatment against persistent HPV in genital (pre)cancerous lesions," Oncology Reports, vol. 10, no. 5, pp. 1437-1441, 2003. 
[10] C.-M. Chuang, A. Monie, C.-F. Hung, and T.-C. Wu, “Treatment with Imiquimod enhances antitumor immunity induced by therapeutic HPV DNA vaccination," Journal of Biomedical Science, vol. 17, no. 1, article 32, 2010.

[11] L. O. Sarian, S. F. M. Derchain, L. A. A. Andrade, J. Tambascia, S. S. Morais, and K. J. Syrjänen, "HPV DNA test and Pap smear in detection of residual and recurrent disease following loop electrosurgical excision procedure of high-grade cervical intraepithelial neoplasia," Gynecologic Oncology, vol. 94, no. 1, pp. 181-186, 2004.

[12] C. Facchini, G. A. Eremita, and A. Bernabei, "Combination of beta-interferon and laser-CO2 therapy in female HPV genitalis," Minerva Ginecologica, vol. 48, no. 9, pp. 345-349, 1996.

[13] P. Nieminen, M. Aho, M. Lehtinen, E. Vesterinen, A. Vaheri, and J. Paavonen, "Treatment of genital HPV infection with carbon dioxide laser and systemic interferon alpha-2b," Sexually Transmitted Diseases, vol. 21, no. 2, pp. 65-69, 1994.

[14] J. Chen, W. Gu, L. Yang et al., "Nanotechnology in the management of cervical cancer," Reviews in Medical Virology, vol. 25, pp. 72-83, 2015.

[15] K. Morshed, D. Polz-Gruszka, M. Szymański, and M. PolzDacewicz, "Human Papillomavirus (HPV)—structure, epidemiology and pathogenesis," Otolaryngologia Polska, vol. 68, no. 5, pp. 213-219, 2014.

[16] M. Stanley, "The epidemiology and burden of HPV disease," Nursing Times, vol. 104, no. 36, pp. 38-40, 2008.

[17] D. Ertoy Baydar, I. Kulac, A. Ozagari, and G. Guler Tezel, "Occurrence of dysplasia and human papilloma virus typing in penile condylomas," Urology, vol. 81, no. 1, pp. 211.e9-211.e15, 2013.

[18] E. Beerens, L. van Renterghem, M. Praet et al., "Human papillomavirus DNA detection in women with primary abnormal cytology of the cervix: prevalence and distribution of HPV genotypes," Cytopathology, vol. 16, no. 4, pp. 199-205, 2005.

[19] I. Salimović-Bešić, A. Tomić-Čiča, A. Smailji, and M. Hukić, "Comparison of the detection of HPV-16, 18, 31, 33, and 45 by type-specific DNA- and E6/E7 mRNA-based assays of HPV DNA positive women with abnormal Pap smears," Journal of Virological Methods, vol. 194, no. 1-2, pp. 222-228, 2013.

[20] P. G. Rossi, M. Benevolo, A. Vocaturo et al., "Prognostic value of HPV E6/E7 mRNA assay in women with negative colposcopy or CIN1 histology result: a follow-up study," PLoS ONE, vol. 8, no. 2, Article ID e57600, 2013.

[21] A. Vince and S. Ž. Lepej, "Diagnostic methods and techniques in cervical cancer prevention Part II: molecular diagnostics of HPV infection," Medicinski Glasnik, vol. 7, no. 1, pp. 18-25, 2010.

[22] W. Weichert, C. Schewe, C. Denkert, L. Morawietz, M. Dietel, and I. Petersen, "Molecular HPV typing as a diagnostic tool to discriminate primary from metastatic squamous cell carcinoma of the lung," The American Journal of Surgical Pathology, vol. 33, no. 4, pp. 513-520, 2009.

[23] K. D. Tardif, K. E. Simmon, Ø. Kommedal, M. T. Pyne, and R. Schlaberg, "Sequencing-based genotyping of mixed human papillomavirus infections by use of ripseq software," Journal of Clinical Microbiology, vol. 51, no. 4, pp. 1278-1280, 2013.

[24] L. Shi, H. L. Sings, J. T. Bryan et al., "GARDASIL: prophylactic human papillomavirus vaccine development-from bench top to bed-side," Clinical Pharmacology \& Therapeutics, vol. 81, no. 2, pp. 259-264, 2007.
[25] A. Monie, S.-W. D. Tsen, C.-F. Hung, and T.-C. Wu, "Therapeutic HPV DNA vaccines," Expert Review of Vaccines, vol. 8, no. 9, pp. 1221-1235, 2009.

[26] A. Tahamtan, A. Ghaemi, A. Gorji et al., "Antitumor effect of therapeutic HPV DNA vaccines with chitosan-based nanodelivery systems," Journal of Biomedical Science, vol. 21, no. 1, article 69, 2014.

[27] S. D. Vernon, D. H. Farkas, E. R. Unger et al., "Bioelectronic DNA detection of human papillomaviruses using eSensor: a model system for detection of multiple pathogens," $B M C$ Infectious Diseases, vol. 3, article 12, 2003.

[28] S. Wang, L. Li, H. Jin et al., "Electrochemical detection of hepatitis B and papilloma virus DNAs using SWCNT array coated with gold nanoparticles," Biosensors and Bioelectronics, vol. 41, no. 1, pp. 205-210, 2013.

[29] D. S. Campos-Ferreira, G. A. Nascimento, E. V. M. Souza et al., "Electrochemical DNA biosensor for human papillomavirus 16 detection in real samples," Analytica Chimica Acta, vol. 804, pp. 258-263, 2013.

[30] D. S. Campos-Ferreira, E. V. M. Souza, G. A. Nascimento et al., "Electrochemical DNA biosensor for the detection of human papillomavirus E6 gene inserted in recombinant plasmid," Arabian Journal of Chemistry, 2014.

[31] L. Civit, A. Fragoso, and C. K. O'Sullivan, "Electrochemical biosensor for the multiplexed detection of human papillomavirus genes," Biosensors and Bioelectronics, vol. 26, no. 4, pp. 1684-1687, 2010.

[32] L. Civit, A. Fragoso, S. Hölters, M. Dürst, and C. K. O’Sullivan, "Electrochemical genosensor array for the simultaneous detection of multiple high-risk human papillomavirus sequences in clinical samples," Analytica Chimica Acta, vol. 715, pp. 93-98, 2012.

[33] R. E. Sabzi, B. Sehatnia, M. H. Pournaghi-Azar, and M. S. Hejazi, "Electrochemical detection of human papilloma virus (HPV) target DNA using MB on pencil graphite electrode," Journal of the Iranian Chemical Society, vol. 5, no. 3, pp. 476-483, 2008.

[34] B. Piro, A. Kapella, V. H. Le et al., "Towards the detection of human papillomavirus infection by a reagentless electrochemical peptide biosensor," Electrochimica Acta, vol. 56, no. 28, pp. 10688-10693, 2011.

[35] S. Jampasa, W. Wonsawat, N. Rodthongkum et al., "Electrochemical detection of human papillomavirus DNA type 16 using a pyrrolidinyl peptide nucleic acid probe immobilized on screen-printed carbon electrodes," Biosensors \& Bioelectronics, vol. 54, pp. 428-434, 2014.

[36] N. Nasirizadeh, H. R. Zare, M. H. Pournaghi-Azar, and M. S. Hejazi, "Introduction of hematoxylin as an electroactive label for DNA biosensors and its employment in detection of target DNA sequence and single-base mismatch in human papilloma virus corresponding to oligonucleotide," Biosensors and Bioelectronics, vol. 26, no. 5, pp. 2638-2644, 2011.

[37] K.-J. Huang, Y.-J. Liu, J.-Z. Zhang, J.-T. Cao, and Y.-M. Liu, "Aptamer/Au nanoparticles/cobalt sulfide nanosheets biosensor for 17beta-estradiol detection using a guanine-rich complementary DNA sequence for signal amplification," Biosensors and Bioelectronics, vol. 67, pp. 184-191, 2015.

[38] L. F. Urrego, D. I. Lopez, K. A. Ramirez, C. Ramirez, and J. F. Osma, "Biomicrosystem design and fabrication for the human papilloma virus 16 detection," Sensors and Actuators B: Chemical, vol. 207, pp. 97-104, 2015.

[39] L. D. Tran, D. T. Nguyen, B. H. Nguyen, Q. P. Do, and H. Le Nguyen, "Development of interdigitated arrays coated with 
functional polyaniline/MWCNT for electrochemical biodetection: application for human papilloma virus," Talanta, vol. 85, no. 3, pp. 1560-1565, 2011.

[40] A. Josefsson, K. Livak, and U. Gyllensten, "Detection and quantitation of human papillomavirus by using the fluorescent $5^{\prime}$ exonuclease assay," Journal of Clinical Microbiology, vol. 37, no. 3, pp. 490-496, 1999.

[41] G. Lizard, M.-C. Chignol, C. Souchier, P. Roignot, Y. Chardonnet, and D. Schmitt, "Detection of low copy numbers of HPV DNA by fluorescent in situ hybridization combined with confocal microscopy as an alternative to in situ polymerase chain reaction," Journal of Virological Methods, vol. 72, no. 1, pp. 15-25, 1998.

[42] M. Siadat-Pajouh, A. Periasamy, A. H. Ayscue et al., "Detection of human papillomavirus Type 16/18 DNA in cervicovaginal cells by fluorescence based in situ hybridization and automated image cytometry," Cytometry, vol. 15, no. 3, pp. 245-257, 1994.

[43] M. Chinami, M. Inoue, K. Masunaga, T. Fukuma, M. Shingu, and T. Toyoda, "Nucleic acid binding by zinc finger-like motif of human papillomavirus type 16 E7 oncoprotein," Journal of Virological Methods, vol. 59, no. 1-2, pp. 173-176, 1996.

[44] S. J. Kim, K. B. Nahm, J. B. Lim, S. W. Oh, and E. Y. Choi, "A rapid and sensitive detection of HPV by combined assay of PCR and fluorescence DNA chip," Biochip Journal, vol. 8, no. 1, pp. 48-54, 2014.

[45] B. J. Kocjan, K. Seme, and M. Poljak, "Detection and differentiation of human papillomavirus genotypes HPV-6 and HPV-11 by FRET-based real-time PCR," Journal of Virological Methods, vol. 153, no. 2, pp. 245-249, 2008.

[46] Y. Xu, Y. Liu, Y. Wu, X. Xia, Y. Liao, and Q. Li, "Fluorescent probe-based lateral flow assay for multiplex nucleic acid detection," Analytical Chemistry, vol. 86, no. 12, pp. 5611-5614, 2014.

[47] S. Pal, A. R. Yadav, M. A. Lifson, J. E. Baker, P. M. Fauchet, and B. L. Miller, "Selective virus detection in complex sample matrices with photonic crystal optical cavities," Biosensors and Bioelectronics, vol. 44, pp. 229-234, 2013.

[48] V. Towne, Q. Zhao, M. Brown, and A. C. Finnefrock, "Pairwise antibody footprinting using surface plasmon resonance technology to characterize human papillomavirus type 16 viruslike particles with direct anti-HPV antibody immobilization," Journal of Immunological Methods, vol. 388, no. 1-2, pp. 1-7, 2013.

[49] S. Wang, H. Yang, H. Zhang et al., "A surface plasmon resonance-based system to genotype human papillomavirus," Cancer Genetics and Cytogenetics, vol. 200, no. 2, pp. 100-105, 2010.

[50] W. Yu-Hong, C. Rui, and L. Ding, "A quantum dots and superparamagnetic nanoparticle-based method for the detection of HPV DNA," Nanoscale Research Letters, vol. 6, no. 1, article 461, 2011.

[51] S. Palantavida, N. V. Guz, C. D. Woodworth, and I. Sokolov, "Ultrabright fluorescent mesoporous silica nanoparticles for prescreening of cervical cancer," Nanomedicine: Nanotechnology, Biology, and Medicine, vol. 9, no. 8, pp. 1255-1262, 2013.

[52] R. Riccò, A. Meneghello, and F. Enrichi, "Signal enhancement in DNA microarray using dye doped silica nanoparticles: application to Human Papilloma Virus (HPV) detection," Biosensors and Bioelectronics, vol. 26, no. 5, pp. 2761-2765, 2011.

[53] W. Wang, D.-W. Pang, and H.-W. Tang, "Sensitive multiplexed DNA detection using silica nanoparticles as the target capturing platform," Talanta, vol. 128, pp. 263-267, 2014.

[54] X. Z. Li, S. Kim, W. Cho, and S.-Y. Lee, "Optical detection of nanoparticle-enhanced human papillomavirus genotyping microarrays," Biomedical Optics Express, vol. 4, no. 2, pp. 187-192, 2013.

[55] W. Fu, Q. Huang, J. Wang, M. Liu, J. Huang, and B. Chen, "Detection of human papilloma virus with piezoelectric quartz crystal genesensors," Sensors \& Transducers Magazine, vol. 42, no. 4, 6 pages, 2004.

[56] D. Dell'Atti, M. Zavaglia, S. Tombelli et al., "Development of combined DNA-based piezoelectric biosensors for the simultaneous detection and genotyping of high risk Human Papilloma Virus strains," Clinica Chimica Acta, vol. 383, no. 1-2, pp. 140146, 2007.

[57] Q. Chen, Z. Bian, X. Hua et al., "Detection of hybridization of single-strand DNA PCR products in temperature change process by a novel metal-clamping piezoelectric sensor," Biosensors and Bioelectronics, vol. 25, no. 9, pp. 2161-2166, 2010.

[58] P. Prakrankamanant, C. Leelayuwat, C. Promptmas et al., "The development of DNA-based quartz crystal microbalance integrated with isothermal DNA amplification system for human papillomavirus type 58 detection," Biosensors and Bioelectronics, vol. 40, no. 1, pp. 252-257, 2013.

[59] P. Parsongdee, T. Limpaiboon, C. Leelayuwat, C. Promptmas, and P. Jearanaikoon, "Development of biosensor for high risk HPV detection in cervical cancer," KKU Research Journal (Graduate Studies), vol. 8, no. 1, 2008.

[60] S. Mobley, S. Yalamanchili, H. Zhang et al., "Procedure for developing linear and Bayesian classification models based on immunosensor measurements," Sensors and Actuators, B: Chemical, vol. 190, pp. 165-170, 2014.

[61] N. Li, S. Franceschi, R. Howell-Jones, P. J. F. Snijders, and G. M. Clifford, "Human papillomavirus type distribution in 30,848 invasive cervical cancers worldwide: variation by geographical region, histological type and year of publication," International Journal of Cancer, vol. 128, no. 4, pp. 927-935, 2011.

[62] J.-H. Su, A. Wu, E. Scotney et al., "Immunotherapy for cervical cancer," BioDrugs, vol. 24, no. 2, pp. 109-129, 2010.

[63] C. Jianrong, M. Yuqing, H. Nongyue, W. Xiaohua, and L. Sijiao, "Nanotechnology and biosensors," Biotechnology Advances, vol. 22, no. 7, pp. 505-518, 2004.

[64] S.-H. Yeom, B.-H. Kang, K.-J. Kim, and S.-W. Kang, "Nanostructures in biosensor-a review," Frontiers in Bioscience, vol. 16, no. 3, pp. 997-1023, 2011.

[65] M. Mehrvar and M. Abdi, "Recent developments, characteristics, and potential applications of electrochemical biosensors," Analytical Sciences, vol. 20, no. 8, pp. 1113-1126, 2004.

[66] R. L. Caygill, G. E. Blair, and P. A. Millner, "A review on viral biosensors to detect human pathogens," Analytica Chimica Acta, vol. 681, no. 1-2, pp. 8-15, 2010.

[67] S. Guo and S. Dong, "Biomolecule-nanoparticle hybrids for electrochemical biosensors," TrAC-Trends in Analytical Chemistry, vol. 28, no. 1, pp. 96-109, 2009.

[68] H. Huang, W. Bai, C. Dong, R. Guo, and Z. Liu, "An ultrasensitive electrochemical DNA biosensor based on graphene/Au nanorod/polythionine for human papillomavirus DNA detection," Biosensors and Bioelectronics, vol. 68, pp. 442-446, 2015.

[69] Rajesh, T. Ahuja, and D. Kumar, "Recent progress in the development of nano-structured conducting polymers/nanocomposites for sensor applications," Sensors and Actuators B: Chemical, vol. 136, no. 1, pp. 275-286, 2009.

[70] D. C. Ferrier, M. P. Shaver, and P. J. W. Hands, "Micro- and nano-structure based oligonucleotide sensors," Biosensors and Bioelectronics, vol. 68, pp. 798-810, 2015. 
[71] I. J. Higgins and C. R. Lowe, "Introduction to the principles and applications of biosensors," Philosophical Transactions of the Royal Society of London. Series B: Biological Sciences, vol. 316, no. 1176, pp. 3-11, 1987.

[72] A. Hulanicki, S. Glab, and F. Ingman, "Chemical sensors: definitions and classification," Pure and Applied Chemistry, vol. 63, no. 9, pp. 1247-1250, 1991.

[73] D. R. Thévenot, K. Toth, R. A. Durst, and G. S. Wilson, "Electrochemical biosensors: recommended definitions and classification," Biosensors \& Bioelectronics, vol. 16, no. 1-2, pp. 121-131, 2001.

[74] P. D’Orazio, "Biosensors in clinical chemistry," Clinica Chimica Acta, vol. 334, no. 1-2, pp. 41-69, 2003.

[75] K. S. Soppimath, T. M. Aminabhavi, A. R. Kulkarni, and W. E. Rudzinski, "Biodegradable polymeric nanoparticles as drug delivery devices," Journal of Controlled Release, vol. 70, no. 1-2, pp. 1-20, 2001.

[76] S. Rahimian, M. F. Fransen, J. W. Kleinovink et al., "Polymeric nanoparticles for co-delivery of synthetic long peptide antigen and poly IC as therapeutic cancer vaccine formulation," Journal of Controlled Release, vol. 203, pp. 16-22, 2015.

[77] J. Devkota, J. Wingo, T. T. T. Mai et al., "A highly sensitive magnetic biosensor for detection and quantification of anticancer drugs tagged to superparamagnetic nanoparticles," Journal of Applied Physics, vol. 115, no. 17, Article ID 17B503, 2014.

[78] X. Zhang, L. Jiang, C. Zhang et al., "A silicon dioxide modified magnetic nanoparticles-labeled lateral flow strips for HBs antigen," Journal of Biomedical Nanotechnology, vol. 7, no. 6, pp. 776-781, 2011.

[79] K. K. Jain, "Applications of nanobiotechnology in clinical diagnostics," Clinical Chemistry, vol. 53, no. 11, pp. 2002-2009, 2007.

[80] R. S. Sethi, “Transducer aspects of biosensors (reprinted from Gec Journal Research Vol 9, Pg 81, 1991)," Biosensors \& Bioelectronics, vol. 9, no. 3, pp. 243-264, 1994.

[81] M.-P. Marco and D. Barceló, "Environmental applications of analytical biosensors," Measurement Science \& Technology, vol. 7, no. 11, pp. 1547-1562, 1996.

[82] P. D’Orazio, "Biosensors in clinical chemistry-2011 update," Clinica Chimica Acta, vol. 412, no. 19-20, pp. 1749-1761, 2011.

[83] C. I. L. Justino, T. A. Rocha-Santos, A. C. Duarte, and T. A. Rocha-Santos, "Review of analytical figures of merit of sensors and biosensors in clinical applications," TrAC Trends in Analytical Chemistry, vol. 29, no. 10, pp. 1172-1183, 2010.

[84] C. Fournier-Wirth and J. Coste, "Nanotechnologies for pathogen detection: future alternatives?” Biologicals, vol. 38, no. 1, pp. 9-13, 2010.

[85] D. Grieshaber, R. MacKenzie, J. Vörös, and E. Reimhult, "Electrochemical biosensors-sensor principles and architectures," Sensors, vol. 8, no. 3, pp. 1400-1458, 2008.

[86] L. C. Clark Jr. and C. Lyons, "Electrode systems for continuous monitoring in cardiovascular surgery," Annals of the New York Academy of Sciences, vol. 102, pp. 29-45, 1962.

[87] D. R. Thevenot, K. Tóth, R. A. Durst, and G. S. Wilson, "Electrochemical biosensors: recommended definitions and classification," Pure and Applied Chemistry, vol. 71, no. 12, pp. 2333-2348, 1999.

[88] N. J. Ronkainen, H. B. Halsall, and W. R. Heineman, "Electrochemical biosensors," Chemical Society Reviews, vol. 39, no. 5, pp. 1747-1763, 2010.
[89] S. Wang, L. Li, H. L. Jin et al., "Electrochemical detection of hepatitis B and papilloma virus DNAs using SWCNT array coated with gold nanoparticles," Biosensors \& Bioelectronics, vol. 41, no. 1, pp. 205-210, 2013.

[90] E. T. Thostenson, Z. Ren, and T.-W. Chou, "Advances in the science and technology of carbon nanotubes and their composites: a review," Composites Science and Technology, vol. 61, no. 13, pp. 1899-1912, 2001.

[91] J. J. Gooding, "Nanostructuring electrodes with carbon nanotubes: a review on electrochemistry and applications for sensing," Electrochimica Acta, vol. 50, no. 15, pp. 3049-3060, 2005.

[92] J. M. Pingarrón, P. Yáñez-Sedeño, and A. González-Cortés, "Gold nanoparticle-based electrochemical biosensors," Electrochimica Acta, vol. 53, no. 19, pp. 5848-5866, 2008.

[93] F. S. R. R. Teles, "Biosensors and rapid diagnostic tests on the frontier between analytical and clinical chemistry for biomolecular diagnosis of dengue disease: a review," Analytica Chimica Acta, vol. 687, no. 1, pp. 28-42, 2011.

[94] M. F. Mitchell, S. B. Cantor, N. Ramanujam, G. TortoleroLuna, and R. Richards-Kortum, "Fluorescence spectroscopy for diagnosis of squamous intraepithelial lesions of the cervix," Obstetrics \& Gynecology, vol. 93, no. 3, pp. 462-470, 1999.

[95] J. Rao, A. Dragulescu-Andrasi, and H. Yao, "Fluorescence imaging in vivo: recent advances," Current Opinion in Biotechnology, vol. 18, no. 1, pp. 17-25, 2007.

[96] F. Chang, S. SyrjÄnen, J. Nuutinen, J. KÄrj̈̈, and K. SyrjÄnen, "Detection of human papillomavirus (HPV) DNA in oral squamous cell carcinomas by in situ hybridization and polymerase chain reaction," Archives of Dermatological Research, vol. 282, no. 8, pp. 493-497, 1990.

[97] I. Abdulhalim, M. Zourob, and A. Lakhtakia, "Overview of optical biosensing techniques," in Handbook of Biosensors and Biochips, John Wiley \& Sons, 2008.

[98] T. J. Park, M. S. Hyun, H. J. Lee, S. Y. Lee, and S. Ko, "A self-assembled fusion protein-based surface plasmon resonance biosensor for rapid diagnosis of severe acute respiratory syndrome," Talanta, vol. 79, no. 2, pp. 295-301, 2009.

[99] A. Olaru, C. Bala, N. Jaffrezic-Renault, and H. Y. Aboul-Enein, "Surface plasmon resonance (SPR) biosensors in pharmaceutical analysis," Critical Reviews in Analytical Chemistry, vol. 45, no. 2, pp. 97-105, 2015.

[100] A. Mitra, B. Deutsch, F. Ignatovich, C. Dykes, and L. Novotny, "Nano-optofluidic detection of single viruses and nanoparticles," ACS Nano, vol. 4, no. 3, pp. 1305-1312, 2010.

[101] D.-S. Xiang, G.-P. Zeng, and Z.-K. He, "Magnetic microparticlebased multiplexed DNA detection with biobarcoded quantum dot probes," Biosensors and Bioelectronics, vol. 26, no. 11, pp. 4405-4410, 2011.

[102] C. Dodeigne, L. Thunus, and R. Lejeune, "Chemiluminescence as a diagnostic tool. A review," Talanta, vol. 51, no. 3, pp. 415439, 2000.

[103] Y.-L. Qiao, J. W. Sellors, P. S. Eder et al., "A new HPV-DNA test for cervical-cancer screening in developing regions: a crosssectional study of clinical accuracy in rural China," The Lancet Oncology, vol. 9, no. 10, pp. 929-936, 2008.

[104] F. R. R. Teles and L. P. Fonseca, "Trends in DNA biosensors," Talanta, vol. 77, no. 2, pp. 606-623, 2008.

[105] A. Tinelli, G. Leo, D. Dell'Edera et al., "Molecular methods for a correct diagnosis of multiple HPV infections and clinical implications for vaccine," International Journal of Gynecological Cancer, vol. 21, no. 3, pp. 545-550, 2011. 
[106] A. Molijn, B. Kleter, W. Quint, and L.-J. van Doorn, "Molecular diagnosis of human papillomavirus (HPV) infections," Journal of Clinical Virology, vol. 32, supplement 1, pp. S43-S51, 2005.

[107] A. Holmberg, A. Blomstergren, O. Nord, M. Lukacs, J. Lundeberg, and M. Uhlén, "The biotin-streptavidin interaction can be reversibly broken using water at elevated temperatures," Electrophoresis, vol. 26, no. 3, pp. 501-510, 2005.

[108] K. Sotlar, D. Diemer, A. Dethleffs et al., "Detection and typing of human papillomavirus by E6 nested multiplex PCR," Journal of Clinical Microbiology, vol. 42, no. 7, pp. 3176-3184, 2004.

[109] A. Roda, M. Mirasoli, S. Venturoli et al., "Microtiter format for simultaneous multianalyte detection and development of a PCR-chemiluminescent enzyme immunoassay for typing human papillomavirus DNAs," Clinical Chemistry, vol. 48, no. 10, pp. 1654-1660, 2002.

[110] Y. Okahata, M. Kawase, K. Niikura, F. Ohtake, H. Furusawa, and Y. Ebara, "Kinetic measurements of DNA hybridization on an oligonucleotide-immobilized $27-\mathrm{MHz}$ quartz crystal microbalance," Analytical Chemistry, vol. 70, no. 7, pp. 12881296, 1998.

[111] I. Burda, A. Silaghi, A. Tunyagi, S. Simon, and O. Popescu, "Note: sensitivity multiplication module for quartz crystal microbalance applications," Review of Scientific Instruments, vol. 85, no. 2, Article ID 026116, 2014.

[112] D. S. Lee and C. S. Chen, "Development of a temperature sensor array chip and a chip-based real-time PCR machine for DNA amplification efficiency-based quantification," Biosensors and Bioelectronics, vol. 23, no. 7, pp. 971-979, 2008.

[113] Y. Mao, C. Luo, and Q. Ouyang, "Studies of temperaturedependent electronic transduction on DNA hairpin loop sensor," Nucleic Acids Research, vol. 31, no. 18, article e108, 2003.

[114] T. Notomi, H. Okayama, H. Masubuchi et al., "Loop-mediated isothermal amplification of DNA," Nucleic Acids Research, vol. 28, no. 12, article e63, 2000.

[115] H.-T. Kuo, J. Z. Yeh, C.-M. Jiang, and M.-C. Wu, "Magnetic particle-linked anti hCG beta antibody for immunoassay of human chorionic gonadotropin (hCG), potential application to early pregnancy diagnosis," Journal of Immunological Methods, vol. 381, no. 1-2, pp. 32-40, 2012.

[116] X. Yi, Y. Ding, Y. Zeng et al., "Magnetic resonance imaging contrast agent: cRGD-ferric oxide nanometer particle and its role in the diagnosis of tumor," Journal of Nanoscience and Nanotechnology, vol. 11, no. 5, pp. 3800-3807, 2011.

[117] D. L. Graham, H. A. Ferreira, and P. P. Freitas, "Magnetoresistive-based biosensors and biochips," Trends in Biotechnology, vol. 22, no. 9, pp. 455-462, 2004.

[118] S. X. Wang and G. Li, "Advances in giant magnetoresistance biosensors with magnetic nanoparticle tags: review and outlook," IEEE Transactions on Magnetics, vol. 44, no. 7, pp. 16871702, 2008.

[119] K. S. Kim, S. Choi, G. J. Lee et al., "Effects of stray field distribution generated by magnetic beads on giant magnetoresistance sensor for biochip applications," in 26th Southern Biomedical Engineering Conference SBEC 2010, April 30-May 2, 2010, College Park, Maryland, USA, vol. 32 of IFMBE Proceedings, pp. 293-296, Springer, Berlin, Germany, 2010.

[120] L. Xu, H. Yu, M. S. Akhras et al., "Giant magnetoresistive biochip for DNA detection and HPV genotyping," Biosensors and Bioelectronics, vol. 24, no. 1, pp. 99-103, 2008. 

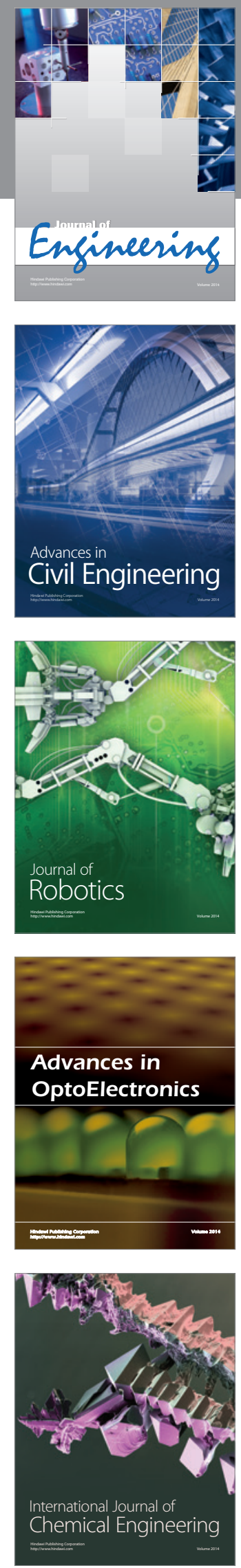

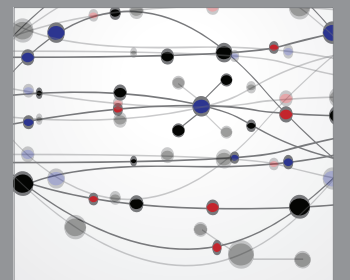

The Scientific World Journal
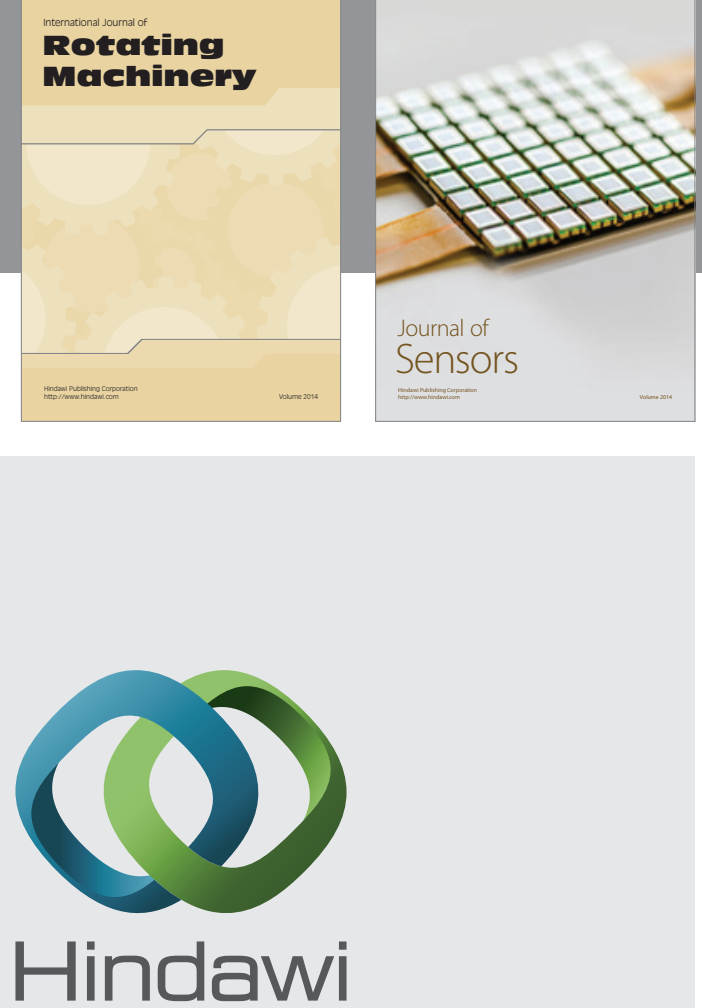

Submit your manuscripts at http://www.hindawi.com
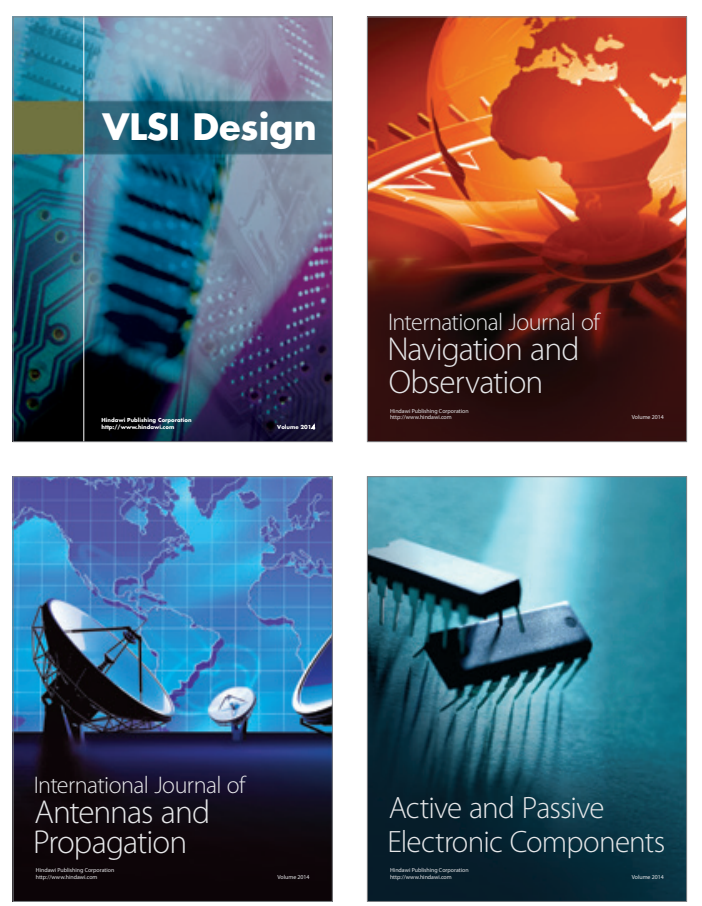
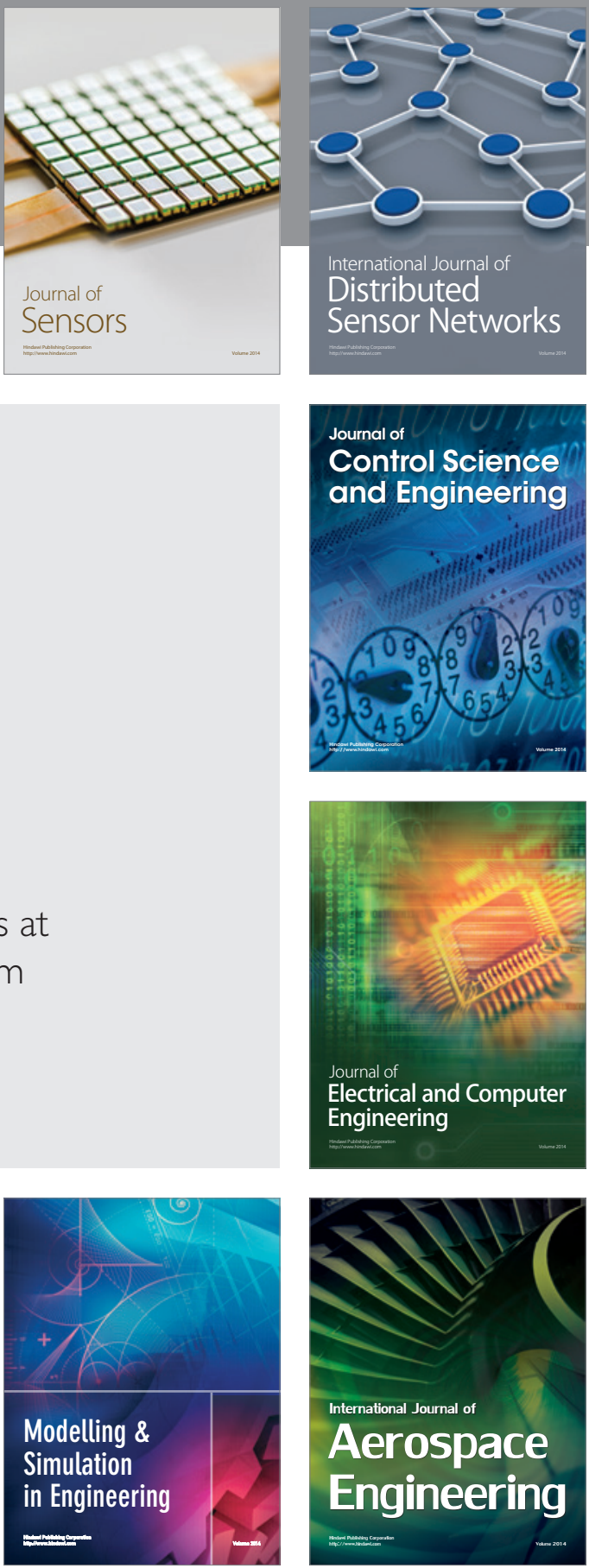

Journal of

Control Science

and Engineering
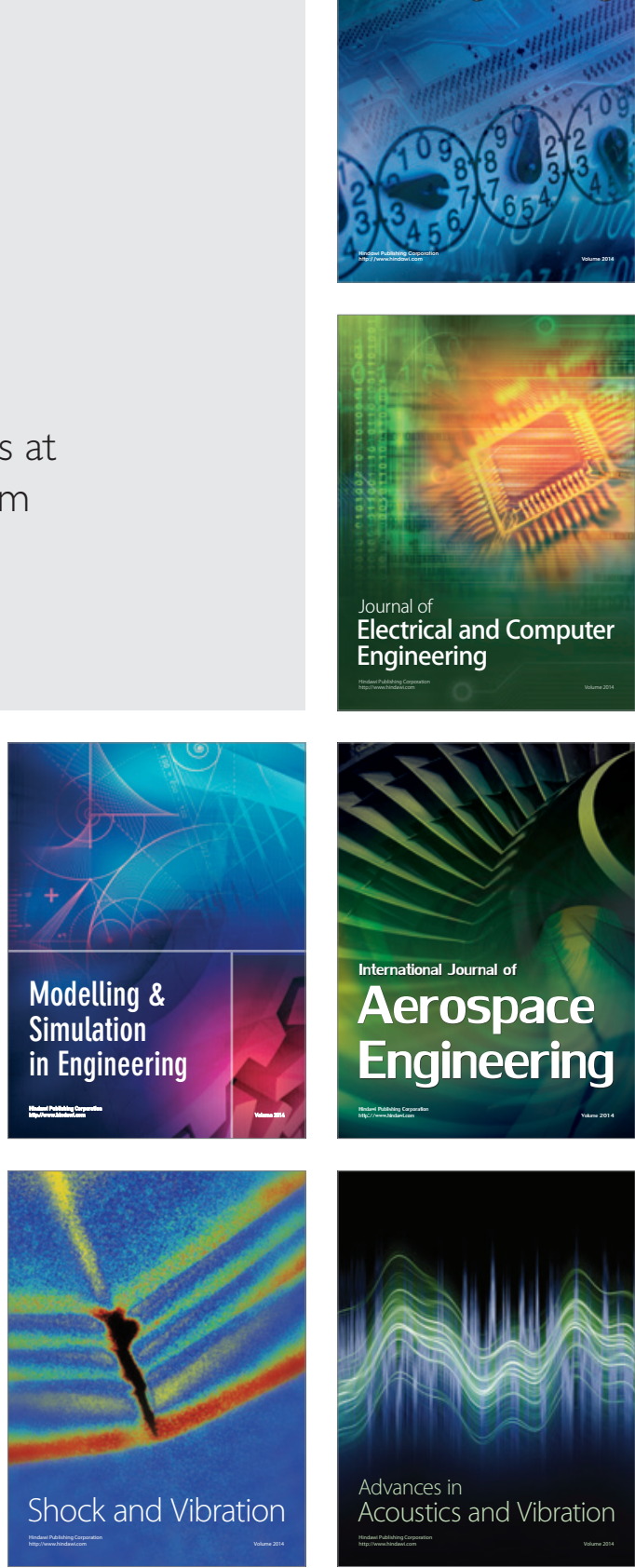